\title{
The Use of Measuring While Drilling and Wireline Logging to Identify the Geological Strata in Qatar
}

\author{
Anna Grace Gravador-Villamor \\ ag gravador@yahoo.com \\ Fugro Peninsular Services Co., Doha, Qatar \\ Fay Pearce \\ f.pearce12@gmail.com \\ Fugro Peninsular Services Co., Doha, Qatar
}

\begin{abstract}
In the field of engineering and construction in the Middle East, it is a common practice to economize a geotechnical investigation using a conventional scope, based on the lowest price. This tends to compromise the project integrity by either under- or over-designing the structure. However, a carefully considered ground investigation and engineering evaluation should be practiced in the early stages, to reduce the unknowns related to geology, ground strength and behavior, ultimately optimizing the geotechnical design, and project constructability and efficiency. This begs the question of whether 'cheap and conventional' can ever equate to 'quality' and what can be done to improve the geotechnical investigations. This paper focuses on ground investigations on rocks and presents the key advantages of utilizing instrumented drilling boreholes in combination with rotary coring boreholes, to collect accurate and good quality data on an accelerated schedule. The study identifies the bias of a conventional geotechnical investigation, highlighting how this can be reduced through the use of instrumented drilling and wireline logging, and how the data collected can define the typical trends observed in the Qatar stratigraphy through correlation from instrumented and rotary coring boreholes drilled in several locations across Qatar. The findings have significant implications on revolutionizing the current ground investigations in Qatar, providing a geotechnical investigation alternative that delivers more complete and high-quality data.
\end{abstract}

Keywords: Geotechnical investigation; Quality geotechnical data; Diagraphy drilling; Instrumented drilling; Wireline logging

\section{INTRODUCTION}

Due to the rockhead in Qatar being generally shallow, the key geotechnical investigation problems encountered are associated with rocks, and comprise the following: (a) efficient determination of the site stratigraphy / geology, (b) the degree of natural fracturing of rocks, (c) rock quality / strength, (d) groundwater and ground hydraulic conductivity, and (e) storage of samples. As there is a general tendency in Qatar for conventional geotechnical investigations, assumed to be applicable across all project sites, the abovementioned key problems relate to traditional scoping that generally involves rotary coring through rocks. This investigation method is largely influenced by the driller's ability to maximize core recovery, and therefore depends on the geotechnical engineer to establish rock parameters based on biased and discrete laboratory testing. 
This paper describes the use of diagraphy / instrumented drilling (monitoring while drilling, MWD) and wireline logging, and how the data collected from these geotechnical investigation methods can aid in: (a) defining the typical trends observed in the Qatar stratigraphy through correlation from instrumented and rotary coring boreholes drilled in several locations across Qatar, and (b) providing a geotechnical investigation alternative that delivers more complete and high quality data for rocks.

\section{GEOTECHNICAL INVESTIGATIONS USING MWD AND WIRELINE LOGGING}

\subsection{MWD}

MWD (BS EN ISO 22475-15, 2016; Measuring While Drilling) is the continuous monitoring of drilling parameters with time/depth, carried out using rotary open hole drilling techniques with fluid flush, and a purpose-built logging unit with a corresponding operating software package. MWD has input and output parameters recorded at every $1 \mathrm{~cm}$ intervals that are characterized by speed and velocity: rotation speed and penetration speed; and those which are characterized by force: thrust on bit and torque. The rotation speed and thrust pressure is set at a constant rate, with the fine feed fully open, and holdback pressure off, allowing for the monitoring of the rigs response to the geology and the identification of any free falls while drilling.

Various formulae are used to derive the interpreted parameters from the input and output parameters: (a) Exponential Method (E-Method), the ratio between the log value of velocity and log value of force, (b) Ease-to-drill (Bingham, 1965; Girard et al., 1986), the ratio between the velocity parameter and the force parameter, (c) specific energy (Teale, 1965), the amount of energy to excavate a cubic meter of material, (d) drilling resistance (Falconer et al., 1988; Girard et al., 1986), the correlation between values of strength and the drilling parameters.

The success rate of this method, relies heavily on the understanding of the method, acquisition tools (type of rig, type of bit, etc.), acquisition procedure, interpretation of the results, and the understanding and continuous collaboration between the driller/s, geotechnical engineer/s and/or engineering geologist/s.

\subsection{Wireline logging}

Wireline logging tools, namely Calliper (CAL) and Natural Gamma Ray (NGR), are recommended to be used with MWD. These tools are used after the borehole is completed to record the borehole diameter (CAL), and the natural radiation retained in the rock (NGR).

Calliper logging can be used to detect cavities and zones of fracturing, as well as the relative strength and homogeneity of the rock. NGR logging can be used to detect depths at which clay is present, and to distinguish the Midra Shale marker bed.

\subsection{Stratigraphic Interpretation of Qatar}

Through interpretation of the MWD and wireline logging results, and correlation with rotary cored boreholes, the geologist/engineer is able to: (a) to distinguish changes in rock formations, (b) to determine the strength parameters of the various rock layers, (c) to identify fractures, and (d) to identify cavities (Gui et al., 2002). The interpretation 
is highly dependent on the engineer's / geologist's ability to understand the geology in which the investigation is taking place, and the ability to recognize the changes in the interpreted parameters with depth and how this corresponds to the changes in geology. This is why it is recommended to have coring boreholes in the investigation (the number is dependent on the number of MWD boreholes).

Data from 9 sites across Qatar (Figure 1) was allowed for the particular characteristics of the Qatar stratigraphy to be analyzed. In general, the Qatar geology follows the sequence of the Damman Formation (Simsima limestone (Umm Bab Member), Dukhan limestone and the Midra Shale formation), the Rus formation, and the Umm Er Radhuma formation. Spatial variations of the sequence are observed, with some units absent.

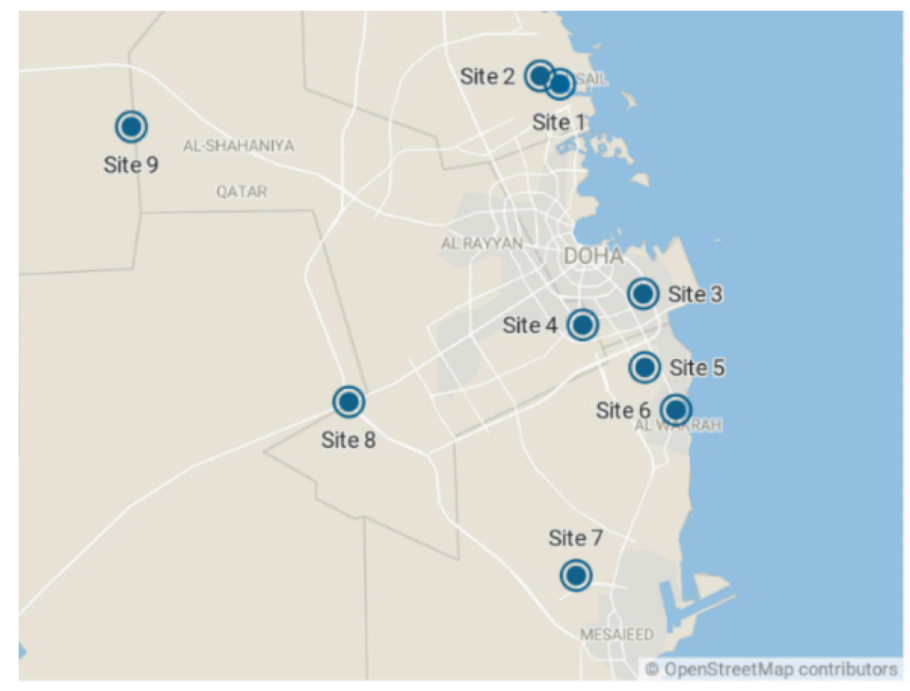

Figure 1: Project sites with MWD

\subsubsection{Simsima limestone (Umm Bab formation)}

The Simsima limestone is a highly heterogeneous rock both vertically and laterally over short distances. The formation tends to be separated into Weathered Simsima Limestone (WSL), Simsima Limestone (SL) and Basal Simsima Limestone (BSL). The characteristics of the Simsima limestone vary greatly, however through the use of MWD it is possible to discern the strength and stability of the rock. Figure 2 illustrates a sample interpretation of Simsima limestone (Umm Bab formation) geologies.

The WSL is typically moderately weak to strong, dolomitized and highly fractured limestone, and can be identified by the heterogeneous behavior in the ease-to-drill, specific energy, penetration speed and calliper readings. The specific energy and hardto-drill can be high due to the strength of the dolomitic limestone. Increased penetration rates, ease-to-drill and torque identify the weaker siltstone/silt and/or claystone/clay layers. Due to the highly fractured nature of the WSL unit, there is usually low recovery of samples and hence, limited tests carried out and rock strength data available.

The SL can either be a competent massive limestone, exhibited by very uniform readings in the penetration speed, specific energy and ease-to-drill. Where the SL has mottling of siltstone and claystone of varying degrees of induration, the readings become 
more heterogeneous, with the specific energy and hard-to-drill sometimes being greater than that observed in the WSL. In places, the SL is a limestone in a siltstone/claystone matrix, where the MWD can identify this through greater penetration speeds, an increase in the ease-to-drill, and a decrease in the specific energy and force vs. velocity ratios, and thus determined as a weaker rock unit.

The BSL tends to exhibit homogenous readings, with constant penetration speed, torque, specific energy (usually lower than the SL) and a constant force vs velocity ratio.

\subsubsection{Dukhan Limestone (DLS)}

Usually the DLS unit is characterized by low penetration speeds, low torque values and high specific energy and hard-to-drill values, and generally more uniform calliper readings. These diagraphy results correlate with the literature on the DLS described as a strong, micro-crystalline, partly recrystallized and dolomitized limestone (Cagatay \& Namik, 1990), fossiliferous and slightly clayey.

\subsubsection{Midra Shale (MSH)}

Generally, the MSH is interbedded shale and limestone, of varying thickness depending on the location in Qatar. The shale beds are typically distinguished by a characteristic low and curved E-method and specific energy values, attributed to the low strength of the shale units. The shale units exhibit high torque values and the specific energy values tend to be greater than that observed in the BSL, not because the formation is stronger but as a result of the friction on the drill bit. Sharp spikes in the E-method, specific energy and hard-to-drill parameters indicate the higher strength limestone beds. Here the use of NGR is an important tool in identifying the MSH, as typical characteristic peaks of 5060 API are observed at this marker bed. Figure 2 illustrates a sample interpretation for Midra Shale in comparison with other geologies.

\subsubsection{Rus Formation (RUS)}

The uppermost part of the Rus formation is a medium strong to strong, dolomitized, buff grey limestone known as the Khor Limestone (KLS) (LeBlanc, 2008). This is reflected in the drilling behavior within the KLS which exhibits low penetration speed, high specific energy and hard-to-drill values (Figure 2). This unit can be highly fractured and recovered as non-intact when coring, with the typical erratic behavior of the rig measurements observed in this unit indicative of this fracturing. Due to the usually low recovery of samples from the KLS unit, limited tests are usually carried out. Hence, there are usually very limited rock strength data available for KLS. Figure 2 illustrates a sample interpretation for KLS.

The underlying RUS is typically an interbedded weak carbonate sequence, becoming a clayey to sulphate sequence, the latter being absent in the northern and central Qatar. The readings from the MWD reflect the interbedding observed in the carbonate RUS which helps to distinguish it from the MSH and the KLS. Generally, there is an evident increase in the ease-to-drill and penetration speeds, with a decrease in the specific energy and force vs. velocity ratio, reflective of this drop in strength. Where there are increases in the hard-to-drill and specific energy, this usually represents the competent, stronger limestone beds (Figure 2). When the carbonate RUS advances to the clayey layers there 
is a significant increase in penetration speed, ease-to-drill and torque, indicative of the lower strength. The stronger gypsum beds tend to have a drop in the penetration speed, and an increase in the specific energy, hard-to-drill, E-method and torque. Figure 2 illustrates a sample interpretation for RUS.

\subsubsection{Umm Er Radhuma (UER)}

The only available diagraphy data comes from two boreholes in the Lusail City area (Site 1 in Figure 1). The rock was described as a moderately weathered, porous dolomitic limestone with thin siltstone/claystone beds. The UER tends to have low penetration speeds, and relatively uniform specific energy and force vs velocity ratios. The ease-todrill and torque increases where the siltstone/claystone beds lie.

\subsection{Sample interpretation of stratigraphy}

Figure 2 illustrates a sample interpretation of stratigraphy based on MWD results from one borehole location in Site 5. Several lithologies have been identified at the location of this specific investigation point: WSL, SL with attapulgitic clay, SL, BSL, MSH, KLS and RUS.

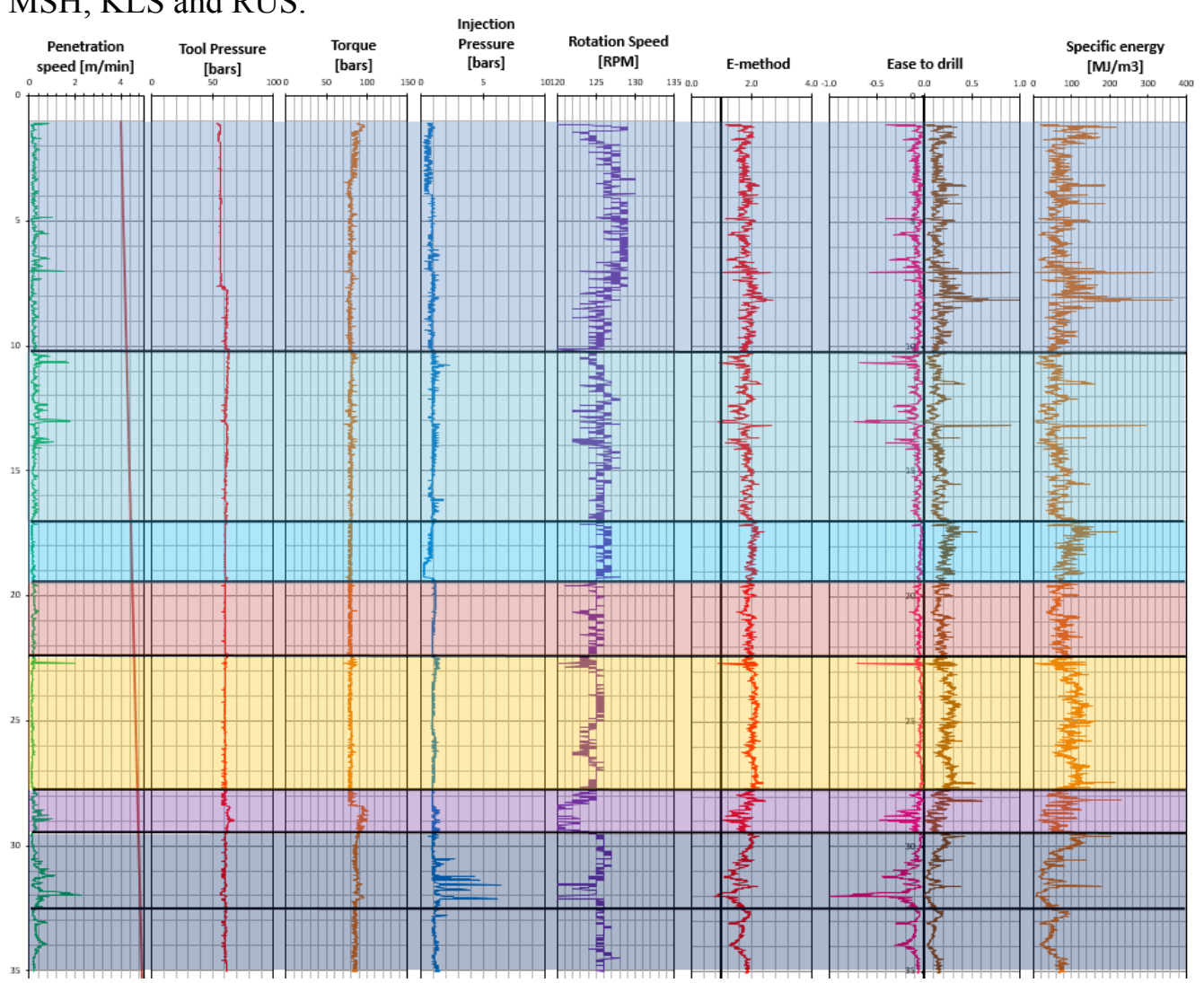

Figure 2: MWD processed results with interpretations for various geologies in Qatar.

The different geologies are represented by various colours from top to bottom: (a) dark blue: WSL, (b) blue: SL with attapulgitic clay; (c) cyan: SL, (d) red: BSL, (e) 
orange: MSH, (f) purple: KLS, (g) dark purple: RUS.

In Figure 2, there are notable differences in the drilling parameters (i.e., penetration speed, tool pressure, torque, injection pressure and rotation speed) as well as in the calculated values for the E-method, hard-to-drill and specific energy, the values of which were studied to aptly provide stratigraphical interpretations. For comparison purposes, the numerical values for specific energy from Figure 2 are summarized in this paper, as follows:

- The calculated specific energy values for Simsima limestone (Umm Bab formation) are as follows: (a) WSL has specific energies ranging between $20 \mathrm{MJ} / \mathrm{m} 3$ to 360 $\mathrm{MJ} / \mathrm{m} 3$, with an approximate average of $50 \mathrm{MJ} / \mathrm{m} 3$, (b) SL with attapulgitic clay has specific energies generally ranging between $20 \mathrm{MJ} / \mathrm{m} 3$ to $140 \mathrm{MJ} / \mathrm{m} 3$, with an approximate average of $50 \mathrm{MJ} / \mathrm{m} 3$, (c) SL has specific energies generally ranging between 60 to $160 \mathrm{MJ} / \mathrm{m} 3$, with an approximate average of $100 \mathrm{MJ} / \mathrm{m} 3$, and (d) BSL has specific energies generally ranging between 40 to $120 \mathrm{MJ} / \mathrm{m} 3$, with an approximate average of $70 \mathrm{MJ} / \mathrm{m} 3$.

- MSH has higher specific energy values than the BSL, with values generally ranging between 60 to $140 \mathrm{MJ} / \mathrm{m} 3$.

- KLS has lower specific energy values than the MSH, with values generally ranging from 20 to $120 \mathrm{MJ} / \mathrm{m} 3$, while RUS has very variable values of specific energy values, which range from 0 to $200 \mathrm{MJ} / \mathrm{m} 3$, due to the presence of interbeds in the carbonate RUS.

It should be noted that the specific energies are only applicable to Figure 2 only. Laterally, these can be correlated on the same investigative site, however, an investigation conducted at another geotechnical site elsewhere in Qatar may exhibit different numerical ranges.

\section{CONCLUSION}

Through the use of MWD it is possible to discern the geological stratigraphy, to aid in the interpretation, knowledge of the local geology, and correlation either from previous coring boreholes or a coring borehole drilled adjacent to a diagraphy borehole. A geotechnical investigation using the conventional coring methods can limit and bias the project with either over- or under-design. When we do coring, we are dependent on the skill of the driller to recover samples sufficient for laboratory testing; when the geology is difficult to recover, our knowledge of that rock is limited, and we tend to use 'engineering judgement' in geotechnical design. As the MWD records at every $1 \mathrm{~cm}$ intervals, a continuous relative-strength record is produced, determining where the rocks are stronger and weaker through the length of the borehole. This is particularly useful where we do not retrieve samples to ascertain the properties of the rock. We can use the drilling resistance parameter to indicate the relative unconfined compressive strength, and with further research, a correlation with the unconfined compressive strength and shear wave velocity can be done.

If we consider the addition of wireline logging, such as calliper and NGR, it is possible to determine the presence of cavities in rock layers. It also enables more accurate interpretation of the geology and aids in understanding of some rock properties such as 
swelling or even the erodibility of the ground in response to the drilling activity.

Instrumented drilling has been a proven technique, with success on several projects in Qatar. The benefits of using MWD have been continuously evident, with a faster project delivery time, borehole data availability within 24 hours of drilling, and more realistic geotechnical design parameters being provided to designers.

Further studies are recommended to be undertaken to derive the correlation between MWD and wireline logging results with Rock Quality Designation (RQD) and hydraulic conductivity. These topics are not touched in this paper.

\section{REFERENCES}

Bingham, M. G. (1965). A new approach to interpreting rock drillability. A technical manual reprinted from the oil and gas journal. $93 \mathrm{p}$.

BS EN ISO 22476-15 (2016). Geotechnical investigation and testing, field testing: measuring while drilling, BSI Standard Publications.

Cagatay, M. \& Namik (1990). Palygorskite in the Eocene rocks of the Dammam Dome. Saudi Arabia Clays and Clay Minerals, Vol. 38, No. 3, 299-307.

Falconer, I. G., Burgess, T. M. \& Sheppard, M. C. (1988). Separating bit and lithology effects from drilling mechanics data. IADC/SPE Drilling Conference, Texas, pp. 123-136.

Girard, H., Morlier, P., Puvilland, O. \& Garzon, M. (1986). The digital ENPASOL method exploitation of drilling parameters in civil engineering. Proc. 39th Canadian Geotechnical Conference, Ottawa, pp. 59-68.

Gui, M. W., Soga, K., Bolton, M.D. \& Hamelin, J. P. (2002). Instrumented borehole drilling for subsurface investigation. Journal of Geotechnical and Geoenvironmental, April, pp. 283-291.

LeBlanc, J. (2008). A fossil hunting guide to the tertiary formations of Qatar, Middle East.

Teale, R. (1965). The concept of specific energy in rock drilling. International Journal Rock Mechanics and Mining Science, Volume 2, pp. 57-73. 